\title{
Novos arranjos em psiquiatria da infância e adolescência no Brasil do século XXI: a prevenção e o controle de risco em foco
}

Letícia Hummel do Amaral'

\section{Resumo}

Discutiu-se, neste artigo, a emergência e a disseminação dos saberes especializados em psiquiatria do desenvolvimento para a infância e adolescência no Brasil. Realizou-se, para tanto, uma investigação bibliográfica e documental - em que se destaca a análise dos relatórios FAPESP anos I e II (INPD, 2018, 2019) que descrevem suas pesquisas e atividades -, e por meio da qual foi possível observar que esses novos arranjos em psiquiatria surgem a partir de sua aproximação às neurociências nas últimas décadas e configuram um modelo teórico cujos fundamentos se assentam em explicações sobre o desenvolvimento cerebral. Estabelecendo uma agenda de pesquisas com crianças e adolescentes recrutados diretamente de algumas escolas selecionadas, os especialistas em psiquiatria do desenvolvimento objetivam identificar cada vez mais precocemente indivíduos em risco de desenvolver os transtornos mentais e, assim, criar tecnologias diagnósticas e terapêuticas que atuem no âmbito da prevenção. $A$ análise das iniciativas realizadas por esse grupo de psiquiatras - pesquisadores na Universidade de São Paulo (UNIFESP), Universidade Federal de São Paulo (USP) e Universidade Federal do Rio Grande do Sul (UFRGS) - ao longo da última década permite afirmar que a legitimação e difusão desse novo paradigma em psiquiatria na sociedade concorre fortemente para a ampliação da medicalização da infância e do espaço escolar no país.

Palauras-chave: Psiquiatria do desenvolvimento. Prevenção. Controle de risco. Medicalização da infância.

I Universidade Federal de Santa Catarina (UFSC), Florianópolis/SC, Brasil. Doutoranda do Departamento de Sociologia e Ciência Política da UFSC. Orcid: https://orcid.org/0000-000 I-7769-5515. Lattes: http://lattes.cnpq. br/92020213304 I36I I. E-mail: leticiahummel@hotmail.com

\section{$(\mathrm{cc}) \mathrm{Br}$}

Direito autoral e licença de uso: Este artigo está licenciado sob uma Licença Creative Commons. Com essa licença você pode compartilhar, adaptar, para qualquer fim, desde que atribua a autoria da obra, forneça um link para a licença, $e$ indicar se foram feitas alterações. 


\section{Introdução}

Este artigo objetiva analisar a emergência de um novo subcampo em psiquiatria no Brasil no século XXI: a psiquiatria do desenvolvimento, que se apresenta como um novo paradigma e cujo marco principal é a inauguração do Instituto de Psiquiatria do Desenvolvimento para a Infância e Adolescência (INPD) em 2009. Conforme especialistas, pesquisas recentes em psiquiatria e neurociências têm evidenciado que a maior parte dos transtornos mentais tem origem na infância, especialmente no desenvolvimento cerebral e, assim, sustenta-se ser possível não apenas identificar precocemente indivíduos em risco para transtornos mentais, inclusive durante o período intrauterino, mas também desenvolver estratégias e tecnologias diagnósticas e terapêuticas que poderiam atuar no âmbito da prevenção, interrompendo processos ditos patológicos, antes mesmo da manifestaçáo da doença.

Várias pesquisas têm sido coordenadas no âmbito do INPD desde sua criação (INPD, 2018, 2019). Para fins deste trabalho, analisa-se a maior e mais onerosa delas, chamada "Conexão - mentes do futuro" ou Brazilian High Risk Cohort Study (BHRCS), que envolveu as três universidades vinculadas ao instituto: Universidade Federal do Estado de São Paulo (UNIFESP), Universidade de São Paulo (USP) e Universidade Federal do Rio Grande do Sul (UFRGS), e avaliou cerca de 10 mil estudantes ${ }^{2}$ de 6 a 22 anos de idade, buscando identificar aqueles em risco para transtornos mentais (CAMPOS, 2019). Tal estudo consiste em uma coorte (pesquisa longitudinal, que acompanha os participantes ao longo do tempo) de crianças e adolescentes selecionados nas cidades de Sáo Paulo e Porto Alegre. É digno de nota que o recrutamento dos participantes para avaliação $(n=9.937)$ tenha sido feito diretamente junto às escolas de ensino básico das duas cidades, fato preocupante que merece a atenção daqueles que pesquisam a medicalização do espaço escolar no Brasil. Os relatórios FAPESP anos I e II (INPD, 2018, 2019) nos fornecem alguns dados importantes, tais como o tamanho da amostra selecionada $(\mathrm{n}=2.511)$, as fases da investigação, os métodos de coleta, além de dados sobre as diferentes categorias em análise em tal pesquisa.

2 Dado obtido em matéria recente do Departamento de Comunicação da Unifesp sobre a pesquisa em questão. Disponível em: https://www.unifesp.br/reitoria/dci/releases/item/4085-projeto-brasileiro-de-psiquiatria-investiga-desenvolvimento-tipico-e-atipico-em-criancas-e-adolescentes 
Assim, a partir de um olhar genealógico à luz de Foucault (2006, 2010, 2011) e por meio de pesquisa bibliográfica e documental - com destaque para a análise dos relatórios acima mencionados -, investigou-se a agenda de pesquisas do INPD, seus fundamentos, objetivos e principais enunciados, buscando desvelar as rupturas e continuidades em termos teóricos-epistemológicos que se apresentam no discurso psiquiátrico em perspectiva histórica. Investigou-se, ademais, a organização interna do INPD, as relaçóes de poder que permeiam sua constituiçáo, identificando seus principais agentes do discurso e da prática. Assim, também foram tomados como objetos de análise os projetos e programas realizados ao longo da última década e as estratégias de disseminação e legitimação dos saberes especializados em psiquiatria do desenvolvimento na sociedade, sobretudo no universo escolar.

Ressalta-se que é inegável os interesses mercadológicos da indústria farmacêutica nas pesquisas realizadas no âmbito do INPD. Conflitos de interesse apontam que Bristol, Novartis, Eli-Lilly, Janssen-Cilag, Abott, Shire, Artes Médicas e Roche apresentam-se como seus mais importantes financiadores privados, fornecendo subsídios para pesquisas, programas de formaçáo médico-continuada, honorários de palestrantes e serviços de consultoria (MIGUEL et al., 2009). Beneficiando-se, portanto, de credibilidade institucional e amplo financiamento para suas iniciativas, observou-se que a consolidação e a disseminação desse novo paradigma em psiquiatria na sociedade, que a propósito já conseguiu espaço para orientar políticas públicas, vêm concorrendo fortemente para a ampliação do processo de medicalização da vida pela psiquiatria, sobretudo no domínio da infância.

\section{Emergência da psiquiatria do desenvolvimento no Brasil}

Anos antes da inauguração do Instituto Nacional de Psiquiatria do Desenvolvimento para a Infância e Adolescência (INPD), já estava em pauta, no campo psiquiátrico, a necessidade de se fortalecer os estudos e a formação profissional especializada em psiquiatria da infância e adolescência. Em publicação do ano 2000 (ROHDE et al., 2000), por exemplo, chama-se a atençáo para novos estudos epidemiológicos internacionais que indicavam que de 10 a $15 \%$ das crianças no mundo seriam portadoras de 
algum transtorno mental. No mesmo texto, porém, admite-se um problema: mesmo com a existência de tal demanda, haveria naquele momento enorme escassez de profissionais habilitados para tratar esse público específico, inclusive em países desenvolvidos. Afirma-se, ainda, que essa realidade (demanda com grandes prejuízos X escassez de serviços) seria certamente ainda mais precária no Brasil. Assim, contra o modelo referencial que se baseia no atendimento de indivíduos com doenças que supostamente são similares ao longo do ciclo da vida, esses autores iráo defender a especificidade das ocorrências, das formas de manifestação e do manejo terapêutico dos transtornos mentais na infância e adolescência (ROHDE et al., 2000).

Alguns anos mais tarde, em carta intitulada: Força-tarefa brasileira de psiquiatras da infância e adolescência (MORAES et al., 2008), os autores afirmam que a International Association for a Child and Adolescent Psychiatry and Allied Professions (IACAPAP) sugeria que os países implementassem um currículo de especialização e pós-graduação de alto nível em psiquiatria da infância e adolescência de forma a garantir um número suficiente de profissionais especializados para atendimento deste público. Chamam a atenção, ainda, para um alerta enviado pela Organização Mundial de Saúde (OMS) a qual, a partir de dados epidemiológicos mais recentes, declarava a necessidade de se haver um psiquiatra infantil trabalhando em período integral para cada 30.000 crianças e adolescentes. Conforme os autores, entretanto, "[...] os psiquiatras infantis brasileiros atendem a uma população 20 vezes maior do que esse número (um para 621.504 indivíduos)" (MORAES et al., 2008, p. 295).

É no âmbito dessas discussóes, portanto, que vai se dar a emergência da psiquiatria do desenvolvimento para a infância e adolescência no Brasil e a criação do INPD, sua principal instituição, em 2009. Um grupo de psiquiatras, notadamente da UNIFESP, USP e UFRGS, adota o referencial da psicopatologia desenvolvimental, uma disciplina que conforme Polanczyck (2009), integra perspectivas epidemiológicas, sociais, genéticas, desenvolvimentais e de psicopatologia para entender as origens e o curso dos transtornos mentais.

Cabe ressaltar que, de acordo com a hipótese desenvolvimental:

[...] os transtornos mentais surgem a partir de inter-relações dimensionais, complexas, em múltiplos níveis, entre características específicas do indivíduo (fatores biológicos, genéticos 
e psicológicos), características ambientais (cuidado parental, relacionamentos interpessoais, exposição a eventos estressores) e sociais (rede de apoio social, vizinhança, nível socioeconômico). (POLANCZYCK, 2009, p. 7).

Com o avanço dos estudos em neurociências e o aprimoramento de técnicas de visualização cerebral, esse grupo de psiquiatras (dentro os quais se destacam: Polanczyck; Bressan; Miguel) coloca no centro do debate e de suas pesquisas: o cérebro, órgão entendido como responsável por orquestrar os processos de desenvolvimento humano (cognitivo, intelectual, emocional e social). Eles buscarão, portanto, encontrar a origem dos transtornos mentais na trajetória de desenvolvimento cerebral (MIGUEL et al., 2009). Desafiam-se a descobrir onde se inicia uma "trajetória (neuro)desenvolvimental atípica” que, futuramente, poderia desencadear a manifestação de sintomas psiquiátricos.

Luís Augusto Rohde, psiquiatra brasileiro renomado internacionalmente e integrante da equipe, advoga pelo potencial inovador da psiquiatria do desenvolvimento e pelo pioneirismo do INPD:

Vamos trabalhar com a identificação de condições subclínicas de transtorno de déficit de atenção, transtorno obsessivo-compulsivo, transtorno de ansiedade, transtorno global do desenvolvimento e de quadros de psicose na infância e adolescência. O que queremos com isto? Aproximar o modelo da psiquiatria do modelo das outras áreas médicas, ou seja, nós vamos estudar aqueles indivíduos em risco de desenvolver o transtorno, que ainda não o desenvolveram, para poder ver quais são os fatores, do ponto de vista genético, de determinantes genéticos, de determinantes ambientais. E, através de neuroimagem, e acompanhá-los na tentativa de poder detectar quais são as trajetórias que levam aqueles indivíduos em risco a desenvolverem os quadros clínicos. Isso também é uma perspectiva inovadora. (ROHDE et al., 2009, p. 21, grifos meus).

Assim, sob a justificativa de que a maior parte dos transtornos mentais tem início em fases precoces da vida e que estes representam as maiores fontes de incapacitação e gastos em saúde pública e também que, conforme dados epidemiológicos, somente $20 \%$ das crianças brasileiras com problemas de saúde mental obtêm acesso a cuidados adequados, a rede de profissionais especializados do INPD organizou uma verdadeira força-tarefa para disseminar nacionalmente os conhecimentos produzidos por suas pesquisas que conjugam os saberes da psicopatologia desenvolvimental, das chamadas neurociências e as novas tecnologias em neuroimagem, e 
objetivam a detecção precoce dos transtornos mentais com vistas à prevenção. A psiquiatria do desenvolvimento (também designada neurociência translacional do desenvolvimento) representa, em outros termos, as neurociências aplicadas à prática clínica psiquiátrica.

O INPD constitui um dos 11 Institutos Nacionais de Ciência e Tecnologia (INCT) do país e conta com o financiamento da Fundação de Amparo à Pesquisa do Estado de São Paulo (FAPESP), do Conselho Nacional de Desenvolvimento Científico e Tecnológico (CNPQ), da Coordenação de Aperfeiçoamento de Pessoal de Nível Superior (CAPES), além daqueles que advêm da indústria farmacêutica e da empresa Nestlé (MIGUEL et al., 2009). O financiamento público das pesquisas apenas para os três primeiros anos girou em torno de 7 milhóes de reais (ROHDE et al., 2009). Dentre os objetivos elencados no site 3 do INPD, ressaltam-se: a realizaçáo de estudos observacionais e experimentais na área de psiquiatria do desenvolvimento; o desenvolvimento de tecnologia para a prevenção dos transtornos mentais; a influência na formação do novo médico sob o referencial da psiquiatria do desenvolvimento; e a criação de novos polos de geração de conhecimento e núcleos de excelência na área de psiquiatria da infância e adolescência no Brasil (INPD, 2020).

Tal instituto foi, então, organizado em torno de sete eixos de trabalho: pesquisa, recursos humanos, transferência de conhecimento para a sociedade, transferência de conhecimento para o setor público e privado, internacionalização, atividades, e produção do INCT; cada qual conta com um coordenador. Cada eixo tem professores e pesquisadores renomados nos campos das neurociências e da psiquiatria, e funcionários das universidades USP, UNIFESP e UFRGS, os quais juntos representam os principais agentes do discurso, da performance e das práticas engendradas conforme o referencial da psiquiatria do desenvolvimento. De acordo com o site, o INPD conta atualmente com mais de 100 pesquisadores colaboradores. Ao final dos anos de 2018 e 2019, os primeiros relatórios produzidos pela instituição, respectivamente FAPESP ano I e FAPESP ano II, foram enviados à FAPESP e publicados em domínio público. Eles constituem materiais de grande importância para este estudo, já que descrevem detalhadamente as

3 Consultar: http://inpd.org.br 
atividades realizadas, aquelas em andamento, ideias para projetos futuros, além de dados sobre gestão e financiamento (INPD, 2019).

Veremos que a prevenção e o controle de risco em saúde mental serão colocados no centro do debate por este novo ramo da psiquiatria, e isso impulsionará novos estudos que objetivam a localização da origem dos transtornos mentais. Entretanto, a este respeito, é importante destacar que, após longos anos de insucessos na localização das causas orgânicas e de marcadores biológicos confiáveis para transtornos mentais (FOUCAULT, 2006, 2010) (CAPONI, 2007), os quais poderiam aproximar efetivamente a psiquiatria da medicina e dar-lhe mais credibilidade, encontra-se no cérebro uma nova possibilidade de achá-los: os agora chamados marcadores neurobiológicos. Mas agora não se trata mais de encontrar necessariamente a doença. Indícios apenas, marcadores de risco são suficientes. A psiquiatria encontra, então, a oportunidade de renovar sua força e legitimidade perante a população. Ressalta-se que o problema da psiquiatria permanece o mesmo desde sua constituição, tal como explicitamente nos colocam seus especialistas: fazer-se valer como ciência médica e aumentar sua credibilidade junto à sociedade.

\section{As neurociências e sua influência na psiquiatria}

O problema da localização orgânica das patologias mentais desde sempre ocupou a psiquiatria. A hipótese sobre a localização cerebral é também bastante antiga, data do século XIX quando a psiquiatria se aproximou da neurologia. Magnan (1835-1916), um psiquiatra francês, já estudava os cérebros post-mortem de pessoas diagnosticadas a fim de localizar possíveis áreas relacionadas às patologias mentais. De acordo com Dutra (2004):

É nesta época que surge a Frenologia, divisão e estudo das áreas cerebrais com suas respectivas funções, numa tentativa de associar as funções mentais com a morfologia do cérebro. Criada por Franz J. Gall (1758-1828), esta teoria sustentava que as diferenças intelectuais e morais entre os homens se deviam a diferenças entre seus cérebros e essas características poderiam ser claramente perceptíveis através da análise da superfície do crânio. Acreditava-se que o desenvolvimento das faculdades mentais das pessoas causava protuberâncias características em determinadas partes do crânio e, através da craniometria, poder-se-ia medir as funções mentais e avaliar a personalidade do indivíduo. (DUTRA, 2004, p. 6). 
Os autores Rose e Abi-Rached (2010), ao lançarem um olhar genealógico para as chamadas neurociências, sustentam que o século XX assistiu à emergência de novas práticas, técnicas e conhecimentos focados no cérebro - a neuroquímica, a neuroendocrinologia, a neurogenética, o neuroimageamento - que podem ser classificados historicamente como uma "terceira onda” das neurociências. Eles lembram que o cérebro havia sido foco de estudo e intervenção pela neurologia do século XVIII e, posteriormente, pela psiquiatria do século XIX. Então, esta terceira onda que ganha força a partir da segunda metade do século XX trouxe a emergência de novos campos de pesquisa sobre o cérebro e o sistema nervoso e podem ser caracterizados pela hibridização de conceitos, métodos e práticas advindas das mais diversas disciplinas, conformando o que conhecemos atualmente como neurociências.

Mais recentemente, sobretudo a partir da década de 1990, há uma redescoberta do cérebro pela psiquiatria (UTTAL, 2001). Novas técnicas de imageamento começam a ser desenvolvidas e trazem como objetivo a possibilidade de aplicação desses conhecimentos na prática médica. Alguns dos novos métodos permitem estudar a estrutura e função do cérebro em um nível muito detalhado, enquanto ele está ativamente engajado em atividades mentais. Entretanto, Uttal (2001), autor que estuda os fundamentos dessa "nova frenologia", faz uma crítica ao que ele chama de (neuro) reducionismo que busca explicar o funcionamento da mente a partir do funcionamento do cérebro. Em analogia ao corpo, cujos órgãos assumem funções diferenciadas, também o cérebro, segundo tal modelo, seria dividido em "órgãos" menores, cada qual com uma função. Essa aproximação explicativa com o modelo do corpo humano acabou, nesse sentido, favorecendo a difusão e a aceitação da teoria da localização cerebral.

A partir da apropriação dos pressupostos neurocientíficos sobre o funcionamento do cérebro "normal", a psiquiatria poderá lançar-se ao objetivo de rastrear o funcionamento anormal do cérebro e, assim, indicar uma localização precisa para a origem das diversas patologias mentais. Ou seja, a psiquiatria contemporânea, ao se aproximar das neurociências e de seus métodos, ganha uma nova chance de alcançar definitivamente o estatuto de ciência médica séria a partir da possibilidade de se encontrar o substrato orgânico das patologias que cria, mas que nunca conseguiu efetiva ou conclusivamente comprovar. 
Segundo Ortega e Zorzanelli (2011, p. 33):

[...] um dos pontos que sustenta o desenvolvimento de uma concepção de indivíduo baseada exclusivamente no cérebro é que, desde a década de 1980, as neurociências passam a incluir no seu rol de preocupações comportamentos sociais e morais. Disso decorre que as psicopatologias passaram, paulatinamente, a ser tratadas como neuropatologias, trazendo a expectativa de ação sobre a máquina cerebral e aumento de sua capacidade de performance. Esse processo é muito bem ilustrado, por exemplo, pela constatação de Racine e Illes (2006) do aumento significativo, ao longo da década de 1990, do número de pesquisas utilizando imageamento por ressonância magnética funcional para abordagem de assuntos previamente privilegiados pelas ciências humanas, como a culpa, a vergonha, a religiosidade. Ou seja, as pesquisas utilizando neuroimagens - métodos que permitem acesso a áreas cerebrais ativadas em determinadas tarefas e funções - são utilizadas não somente para decifrar doenças, mas também a natureza das nossas escolhas sexuais, gostos e características pessoais, sentimentos e experiências.

Assiste-se, portanto, a uma nova forma de (neuro)biologização de questóes morais e sociais, ou ainda, a uma cerebralização de emoções, de comportamentos, de experiências e, também, do sofrimento psíquico (ORTEGA; VIDAL, 2019). No que se refere à psiquiatria contemporânea, as patologias mentais passarão a ser entendidas como transtornos do neurodesenvolvimento.

Em outro artigo, Ortega (2006) problematiza a discurso sobre a autoevidência dos exames de imageamento. Para ele, essas imagens constituem evidências sociotécnicas cuja função é produzir uma aparência de naturalidade e imediação que não nos deixa nenhuma margem de dúvida, mas que, em realidade, acaba por ocultar ou deslocar os contextos e pressupostos socioculturais e econômicos nos quais essa evidência e naturalidade repousam. O fato é que essas imagens por si mesmas não conseguiram, até hoje, provar efetivamente nenhuma relaçáo de causalidade entre os processos cerebrais e as novas patologias mentais.

Rose e Abi-Rached (2013) argumentam ainda sobre os aspectos políticos relacionados à emergência das novas neurociências. Segundo eles, ao longo da última metade do século $\mathrm{XX}$, o cérebro humano passou a ser: anatomizado em nível molecular; entendido por sua plasticidade e mutabilidade ao longo da vida; sofisticadamente adaptado à interaçáo e sociabilidade humanas; e também aberto à investigação em nível molecular e sistêmico, segundo uma variedade de configuraçóes experimentais, dentre as quais destacam-se aquelas envolvendo modelos animais e aquelas 
que utilizam tecnologias de visualização. Essa nova situação gerou um senso de neurobiologia humana que define as condiçóes para a vida mental, moldando sua conduta de diversas formas. Defendem que cada uma das mudanças conceituais que levaram à ideia do cérebro neuromolecular, plástico e visível está intrinsecamente ligada à invenção de novas maneiras de intervir no cérebro, possibilitando novas formas de governar a população através e em nome do cérebro. Assim, a psiquiatria desde sua invenção no século XIX, depara-se com a mesma questão, que nunca pôde ser abandonada:

[...] a questão do que é realmente ser louco, os limites da loucura e sanidade, e a diferenciação entre as várias formas que a loucura - se denominada alienação, doença mental ou transtorno mental - pode tomar. De fato, ela foi assombrada por esse problema, enquadrando-o como o problema do diagnóstico, com teóricos, profissionais e críticos retornando a ele repetidamente (cf. Porter 2002, I). [...] Alguns acham que estamos, finalmente, prestes a deixar esses problemas para trás, que a neurobiologia permitiu à psiquiatria se tornar uma ciência e, à medida que a psiquiatria se torna neuropsiquiatria, será capaz de responder, finalmente, à questão de quem é um caso adequado para tratamento. Um apelo ao cérebro, ou a sequências genéticas específicas associadas a anomalias neurobiológicas específicas, ou à nova visibilidade aparentemente conferida pela neuroimagem, permitirá finalmente que os médicos delineiem os limites da normalidade e diferenciem os distúrbios? A neurociência finalmente fornecerá à psiquiatria a objetividade que ela procura? (ROSE; ABI-RACHED, 2013, p. III).

A psiquiatria do desenvolvimento irá constituir-se fundamentalmente a partir dos pressupostos aqui abordados. Grande parte dos seus esforços de pesquisa relacionam-se à localizaçáo cerebral dos transtornos mentais, ou ainda, dos (neuro)marcadores que indicam o risco para transtornos mentais. Entretanto, embora não tenha sido comprovada até agora a existência de marcadores cerebrais para servir caso a caso nos diagnósticos individuais, essa teoria é afirmada como uma verdade assentada em evidências científicas altamente questionáveis e serve de fundamento para as mais diversas iniciativas junto à população, como veremos, sobretudo, no domínio da infância e adolescência.

\section{O DSM-V, o RDoC e os transtornos do neurodesenvolvimento}

O DSM-V de 2014 é a mais atual edição aprovada do Manual de diagnósticos e estatísticas em psiquiatria e tem sido a referência ${ }^{4}$ mais

4 Além do CID - Classificação Internacional de doenças, lançado pela Organização Mundial da Saúde (OMS), 
utilizada mundialmente tanto em pesquisa como na prática diagnóstica de patologias mentais. Em seu prefácio, o DSM-V traz como mudança, dentre outras coisas, a inauguração dos transtornos do neurodesenvolvimento. Porém, a questão da inexistência de marcadores biológicos é admitida:

DSM-V apresenta diferenças substanciais em relação às edições anteriores. Vindo na mesma linha de procura de uma cada vez mais ampla utilidade clínica e de melhoria da fiabilidade dos diagnósticos, acrescentou-se a necessidade de incorporar modernos dados científicos, em áreas tão diversas como as neurociências ou a epidemiologia, com o objetivo de incrementar a validade dos diagnósticos. A questão da validade é um dos problemas centrais da Psiquiatria. Apesar de numerosos estudos científicos, sabemos não existir ainda uma validade biológica que possa fundamentar a grande maioria das categorias diagnósticas. A classificação é baseada quase exclusivamente na catalogação de critérios sintomáticos e no seu agrupamento em categorias consensualmente aceites. (ASSOCIAÇÃO AMERICANA DE PSIQUIATRIA, 2014, p. VII).

Como veremos, embora a psiquiatria tenha incorporado nas últimas décadas os pressupostos neurocientíficos, as fragilidades epistemológicas de suas categorias diagnósticas têm sido alvo de investigação e crítica por diversos autores, não apenas de outras áreas do saber - como as ciências humanas, a psicanálise e a saúde coletiva, mas também pelos próprios psiquiatras ${ }^{5}$.

Rohde (2013), especialista em psiquiatria do desenvolvimento com foco nos estudos sobre TDAH, foi o único brasileiro convidado a fazer parte da força-tarefa da APA para a elaboração do DSM-V (2014), revisando os critérios de definição de transtornos mentais. Em entrevista concedida à Folha (ROHDE, 2013), ele também admite que falta base biológica aos diagnósticos:

Quando entrei no esforço de revisão do DSM, eu tinha o desejo e a fantasia de que seria possível ter uma modificação de paradigma na forma de se fazer diagnóstico psiquiátrico.

atualmente em sua $10^{\text {a }}$ edição. A CID-10 é o critério adotado no Brasil pelo Sistema Único de Saúde (SUS). Ele abrange todas as doenças, incluindo os transtornos mentais.

5 O site Madinamerica e também sua versão brasileira Madinbrasil: ciência, psiquiatria e justiça social, por exemplo, são uma iniciativa do campo da psiquiatria crítica cujo objetivo principal é repensar criticamente a psiquiatria e, assim, construir um novo paradigma de assistência psiquiátrica. Três temas norteadores do site, que faz publicações periódicas, merecem destaque: por que os resultados de longo prazo são tão pobres para a grande maioria dos transtornos mentais? Por que há essa lacuna tão grande entre, de um lado, o que a literatura científica diz a respeito dos transtornos mentais e seu tratamento e, do outro lado, o que é dito pela psiquiatria ao público? E finalmente, por que as vozes daqueles que são tratados pela psiquiatria têm sido historicamente abafadas?. Disponível em: https://madinbrasil.org/mission/ 
Nós queríamos a inclusão de marcadores neurobiológicos [sinais físicos do funcionamento do cérebro e do sistema nervoso] na prática clínica. Queríamos aproximar a psiquiatria de um estágio de desenvolvimento onde está a oncologia, por exemplo. O que aconteceu foi que, ao revisar o que existia de evidência científica dentro da área de psiquiatria, constatamos claramente que ainda não estamos prontos para uma mudança de paradigma. Isso gerou na comunidade científica uma certa sensação de frustração. Mas foi possível fazer algo extremamente importante: analisar o que poderia ser melhorado nos critérios diagnósticos e revisá-los à luz da medicina baseada em evidências, para torná-los mais válidos. Isso levou em conta tudo o que foi feito de pesquisa durante esses 29 anos. (ROHDE, 2013, [s. p.], grifos meus)

Ressalta-se, nesse sentido, que os novos diagnósticos - os transtornos do neurodesenvolvimento - integraram o DSM-V (2014), amplamente utilizado nos últimos anos, sem que tenham sido conclusivamente comprovadas as origens neurobiológicas dos transtornos mentais. Allen Frances (2015), psiquiatra que integrou a equipe de produção do DSM anterior (DSM-IV), corrobora o sentimento de fracasso e frustração no campo psiquiátrico:

O DSM-V sofre a infeliz combinação de ambições excessivamente elevadas e de uma metodologia frouxa. Sua esperança otimista era criar um avanço revolucionário na psiquiatria; em vez disso, o triste resultado é um manual que não é nem seguro nem cientificamente correto. Por exemplo, ele introduziu três novos transtornos que permeiam o tênue limite da normalidade: Transtorno de Compulsão Alimentar, Transtorno Neurocognitivo Leve e Transtorno Disruptivo da Desregulação do Humor. A menos que esses diagnósticos sejam usados com moderação, milhões de pessoas essencialmente normais serão mal diagnosticadas e submetidas a tratamentos potencialmente danosos e estigma desnecessário. O DSM-V também reduziu os requerimentos para diagnosticar transtornos existentes; por exemplo, duas semanas de luto normal se transformaram em Transtorno Depressivo Maior. (FRANCES, 2015, p. 5).

Para ele, aquilo que tem sido abordado como uma epidemia real de transtornos mentais não passa de uma epidemia de diagnósticos desinformados e hábitos de prescrição descuidados. "Mudanças mínimas em como os transtornos são definidos e em como os critérios de diagnósticos são aplicados podem resultar em alteraçôes enormes nos índices de transtornos relatados e no uso de medicamentos" (FRANCES, 2015, p. 5). A esse processo chamamos de inflação de diagnósticos falso-positivos.

Mais recentemente, outros autores do campo da psiquiatria, tal como cita Brunoni (2017), reafirmam a crítica ao modelo do DSM. Em artigo 
intitulado Beyond DSM - trends in diagnoses, o autor argumenta que, embora este manual seja amplamente usado, ele tem baixa validade, já que pacientes com diferentes transtornos mentais dividem comumente sintomas parecidos; em outras palavras, há uma sobreposição de sinais e sintomas entre diferentes diagnósticos. Ele defende que, de fato, o sistema diagnóstico do DSM tem sido considerado hoje um dos principais obstáculos para os avanços nas pesquisas em psiquiatria. O que se propóe é que a nosologia psiquiátrica (classificaçáo de doenças) seja reformulada de acordo com uma etiologia (definição das causas) biologicamente fundamentada, e não com base em agrupamento de sintomas, tal como tem sido feito no DSM desde a terceira edição (1980).

Atualmente, já existe uma proposta de reconfiguração das categorias diagnósticas, a chamada Research Domain Criteria (RDOC) a qual, aliada ao referencial da psiquiatria do desenvolvimento, promete ser útil, conforme Brunoni (2017), aos esforços para se desenvolver uma nosologia ancorada na etiologia das doenças. O projeto $\mathrm{RDoC}$ é coordenado por Thomas Insel - atualmente diretor do National Institute of Mental Health (NIMH) - e objetiva desenvolver novas formas de classificar as patologias mentais baseadas em dimensóes de comportamentos observáveis e medidas neurobiológicas. Cabe ressaltar que o que está em questão neste debate bastante atual é novamente a antiga dificuldade da psiquiatria em integrar etiologia (origem das doenças) e nosologia (suas classificaçôes).

Como veremos, a replicaçáo dos achados de pesquisas para a prática diagnóstica em psiquiatria clínica transformou-se no grande problema da neuropsiquiatria contemporânea. Todos seus esforços de pesquisa caminham agora nessa direção. É uma transformação silenciosa, mas revolucionária, que está acontecendo com a elaboração desses novos critérios diagnósticos, o que merece a atenção de novos estudos. Citando também Insel (2013), os autores Ortega e Vidal (2019) afirmam que a partir do RDoC, os biomarcadores não serão mais relacionados a categorias do DSM, “[...] mas as doenças mentais continuarão a ser definidas como transtornos biológicos envolvendo circuitos cerebrais que implicam domínios específicos de cognição, emoção ou comportamento" (ORTEGA; VIDAL, 2019, p. 174).

Cabe observar, portanto, que se o DSM-V vem perdendo legitimidade no campo acadêmico, outro manual está em vias de ser elaborado a partir 
do RDoC e promete trazer a tão sonhada fundamentação etiológica para as patologias mentais. Como vimos, o DSM-V (2014) resultou, em grande medida, da adoção do referencial da psiquiatria do desenvolvimento, mas a grande decepção foi por não ter conseguido incluir os marcadores neurobiológicos como critérios diagnósticos do manual, consequência do então fracasso das pesquisas que tinham esse intuito. No entanto, ressalta-se que muitas pesquisas continuam em andamento e prometem apresentar resultados mais conclusivos em um futuro próximo.

\section{A problemática do risco e da prevenção no campo da saúde mental}

Uma das maiores contribuições de Foucault em suas análises sobre a experiência da modernidade relaciona-se ao núcleo teórico do biopoder. Esse tipo de poder que aparece no século XIX centra-se no corpo e na vida, em sua preservação e melhoramento. Em estreita relação ao desenvolvimento do capitalismo, o biopoder objetiva criação de corpos dóceis e produtivos ao sistema. Ele é, ao mesmo tempo individualizante e totalizante. Volta-se, portanto, ao governo do indivíduo por meio de técnicas disciplinares, e da população (como corpo-espécie) por meio de mecanismos de regulação, a denominada biopolítica. Conforme o autor, o biopoder “[...] trata essencialmente de aumentar a vida, de prolongar sua duração, de multiplicar suas possibilidades, de desviar seus acidentes, ou então de compensar suas deficiências" (FOUCAULT, 1999 p. 304).

Conforme Foucault, é a partir da lógica do risco e da segurança associada à legitimação de certos saberes, tais como a biomedicina, a estatística e a epidemiologia, que se torna possível o governo das populaçóes.

Porque, afinal de contas, para de fato garantir essa segurança é preciso apelar, por exemplo, e é apenas um exemplo, para toda uma série de técnicas de vigilância, de vigilância dos indivíduos, de diagnóstico do que eles são, de classificação da sua estrutura mental, da sua patologia própria etc., todo um conjunto disciplinar que viceja sob os mecanismos de segurança para fazê-los funcionar. (FOUCAULT, 2008, p. II).

Seguindo esta ótica, portanto, os dispositivos de saber-poder próprio das sociedades liberais e neoliberais, designado por Foucault de 
"dispositivo de segurança”, vai se centrar na lógica da prevenção e antecipação de riscos. Conforme Caponi (2019, p. 172):

Esse dispositivo não tem o propósito de fechar ou isolar num espaço; pelo contrário, permite a circulação de saberes em espaços diversos, passando por escola, família, psicologia, educação, dentre outros âmbitos. Trata-se de um poder que não estabelece distinções taxativas entre o normal e o patológico, o certo e o errado, mas que se situa num contínuo que integra desde as patologias mais graves até os pequenos desvios de comportamento. Um poder, que, por fim, adota uma perspectiva não individual, mas populacional, estabelecendo parâmetros estatísticos de normalidade e desvio, além de estratégias de normalização para aqueles que não se ajustam aos critérios de existência definidos de acordo com curvas de normalidade.

Assim, observa-se que a psiquiatria do desenvolvimento sob a justificativa de que a maior parte dos transtornos mentais dos adultos tem origem na infância, especialmente no desenvolvimento cerebral, trabalha essencialmente com a noção de indivíduos em risco e com tecnologias para a antecipação do risco. Seu discurso sobre a existência de um risco generalizado em saúde mental penetra o ambiente escolar, e por meio da mídia, informa a população geral. Seus principais agentes afirmam uma nova verdade e apresentam dados estatísticos que geram medo na população e, portanto, a necessidade de consumir seus serviços. Essa verdade, a propósito, a convida igualmente a participar de suas pesquisas e a ganhar, com isso, uma avaliação gratuita que dirá se o indivíduo está ou não em risco de desenvolver um ou mais transtornos mentais. Seus discursos e práticas ancorados na noção de risco expressam, assim, uma biopolítica da população infanto-juvenil que está centrada em uma grande variedade de controles e intervençóes reguladoras de seu desenvolvimento futuro: emocional, cognitivo/comportamental e social.

Nesse sentido, atualmente, os médicos já não diagnosticam e tratam enfermidades, mas diagnosticam e tratam riscos. Como os riscos nem sempre se convertem em doença, é possível afirmar que estamos diante de uma situaçáo inédita na prática médica em que existem efeitos adversos de diagnósticos e tratamentos de doenças que nunca ocorreram. (CASTIEL; ALVAREZ-DARDET, 2010) Ademais, os riscos que se afirmam estar presentes no campo da saúde mental infanto-juvenil reproduzem-se 
nos discursos psiquiátricos como um problema que pode não apenas afetar a vida da própria criança ou adolescente (mencionam-se a probabilidade de evasão escolar, prejuízo acadêmico/profissional e na vida social, além de problemas com a justiça), como pode impactar negativamente o futuro da sociedade em geral (GIUSTI, 2016).

A partir deste estudo, pode-se afirmar a este respeito que é, de fato, recorrente o argumento inicial em artigos e matérias do âmbito da psiquiatria do desenvolvimento sobre o excesso de gastos com saúde mental no mundo e o impacto que isso gera nas contas públicas. Então, a promessa que se apresenta é que tal problema pode ser revertido com políticas de antecipação de riscos e de intervençôes preventivas. Defende-se que o quanto antes a intervenção for feita, menos onerosos serão os gastos com as políticas de saúde mental. Conforme Caponi (2019), observa-se que a estratégia de intervenção precoce na infância para prevenir problemas na vida adulta pela psiquiatria é mais antiga do que parece.

Se observarmos as publicidades da indústria farmacêutica, faz tempo que a intervenção preventiva na infância com psicofármacos, desde o Thorazine (1956) até a Ritalina (1970), apresenta-se como um modo de evitar os problemas psiquiátricos que poderiam surgir na vida adulta, no caso de crianças com certo perfil como desatenção, desinteresse ou desobediência, não fossem devidamente tratadas. (CAPONI, 2019, p. 172).

Cabe entender de forma crítica, portanto, os usos políticos que têm sido feitos da ideia de risco pela psiquiatria contemporânea. De acordo com Castiel e Alvarez-Dardet (2010), não se trata de menosprezar o poder de conhecimento que temos disponível sobre o risco - importante nas técnicas e conjuntos de práticas com vistas à prevenção de enfermidades a nível populacional - mas antes, de "[...] assinalar tantos os possíveis efeitos dos exageros em sua utilização como também sua vinculação com aspectos indesejáveis das atuais configuraçóes socioculturais que devem ser aperfeiçoadas" (CASTIEL; ALVAREZ-DARDET, 2010, p. 64).

Assim, para Castel (2008) - importante autor que se debruça sobre esta temática - existe uma preocupação excessiva com os riscos na sociedade contemporânea que se ancora em um mito, uma vez que:

[...] não há riscos em si mesmos, o risco sempre se refere a uma situação social histórica particular, onde há, por exemplo, proteções, mas essas proteções são consideradas insufi- 
cientes e há uma aspiração por segurança muitas vezes excessiva, porque não há segurança absoluta, a menos que se esteja morto, quando se morre, nada pior pode acontecer. [...] Outra coisa acontece se se raciocina em termos de população de risco, porque não temos que esperar que se produza um ato indesejável, não se constata um perigo, mas se constrói uma combinação de fatores suscetíveis de produzi-lo, que o torna mais ou menos provável. (CASTEL, 2008, p. 2-3, tradução minha).

Na mesma linha crítica, no que tange aos usos da noção de risco em saúde e à política de vigilância sanitária criada a partir de cálculos probabilísticos, Rabinow (1999, p. 1945) sustenta que:

A prevenção moderna é antes de tudo o mapeamento de riscos. O risco não é o resultado de perigos específicos colocados pela presença imediata de uma pessoa ou um grupo de pessoas, mas sim a fusão de "fatores" impessoais que tornam um risco provável. Assim, a prevenção é a vigilância, não do indivíduo, mas sim de prováveis ocorrências de doenças, anomalias, comportamentos desviantes a serem minimizados, e de comportamentos saudáveis a serem maximizados.

É interessante notar aqui, tal como sustenta Rabinow (1999), que a psiquiatria do desenvolvimento trabalha não apenas na linha da prevenção e gestão de riscos, mas contempla também uma preocupação com a maximização de comportamentos saudáveis. O lócus privilegiado para esse último empreendimento é, sobretudo, a escola. As chamadas "competências socioemocionais", referenciadas na Base Nacional Comum Curricular (BNCC, 2018) ${ }^{6}$ - autoconsciência, autogestão, consciência social, habilidades de relacionamento, tomada de decisão responsável - têm sido apontadas como fatores protetores ao desenvolvimento de transtornos mentais e as intervençóes propostas para seu fortalecimento foram designadas aos professores e pais, e quando não funcionam, à psicologia de abordagem cognitiva-comportamental, que trabalha no âmbito da orientação de condutas com vistas à adaptação social. A aquisição dessas habilidades socioemocionais ocupa atualmente o lugar daquilo que é considerado normal/saudável. Portanto, ela deve, segundo tal perspectiva, ser perseguida e maximizada.

6 Disponível em: http://basenacionalcomum.mec.gov.br/implementacao/praticas/caderno-de-praticas/aprofundamentos/ 195-competencias-socioemocionais-como-fator-de-protecao-a-saude-mental-e-ao-bullying. 
Cabe lembrar que a medicina em geral, e assim também a psiquiatria, trabalham estrategicamente com a própria autoridade cultural que lhes foram concedidas historicamente (MITJAVILA 2015). Seu discurso náo é, portanto, imposto de cima para baixo diretamente. É justamente pela estratégia do medo e do risco que o saber médico atua para perpetuar sua legitimidade e poder no controle social. Em outro artigo, Caponi (2012) faz uma análise do que ela chama de "biopolítica do sofrimento psíquico" e sua estreita relação com a ideia de "risco":

O risco, na medida em que aparece como um modo de antecipar um perigo possível (real ou imaginado) sobre a vida e a saúde, constitui a estratégia biopolítica por excelência que permite garantir a legitimidade e aceitabilidade desse modo de exercer o governo das populações. A ambição por identificar comportamentos de risco cada vez mais sutis, com a finalidade de construir uma psiquiatria preventiva, é central para compreender o modo como os pequenos desvios de conduta e as tristezas cotidianas ingressam no campo das intervenções psiquiátricas, iniciando um verdadeiro processo de medicalização do não patológico. (CAPONI, 2012, p. 117).

É importante destacar, portanto, que as mais recentes classificações diagnósticas de transtornos mentais foram definidas a partir da noção de risco, assim como as novas intervençôes psiquiátricas propostas se justificam a partir dela. Categorias como "indivíduos em risco", "marcadores de risco", "escore de risco" são centrais para esse novo paradigma. Ou seja, esta pesquisa mostrou que risco e prevençáo constituem conceitos-chave à psiquiatria do desenvolvimento, sendo mobilizados e difundidos como estratégia biopolítica de legitimação e disseminação do seu saber-poder na sociedade, e assim como tecnologia de governo das populaçóes, sobretudo no domínio da infância e adolescência.

\section{$6 \mathrm{~A}$ agenda de pesquisas do Instituto Nacional de Psiquiatria do Desenvolvimento para a Infância e Adolescência (INPD)}

Diferentes pesquisas têm sido coordenadas pelo INPD desde sua criação. Nesta seção é analisada a maior delas, chamada: "Conexão - mentes do futuro" ou Brazilian High Risk Cohort Study (BHRCS), que envolveu três universidades (Unifesp, USP e UFRGS) e avaliou cerca de $10 \mathrm{mil}$ 
estudantes de 6 a 22 anos de idade, buscando identificar aqueles em risco para transtornos mentais (CAMPOS, 2019). Este estudo consiste em uma coorte (pesquisa longitudinal, que acompanha os participantes ao longo do tempo) de crianças e adolescentes selecionados nas cidades de Sáo Paulo e Porto Alegre. É digno de nota que o recrutamento dos participantes para avaliação $(n=9.937)$ tenha sido feito diretamente junto às escolas de ensino básico das duas cidades, fato preocupante que merece a atenção daqueles que pesquisam a medicalização do espaço escolar no Brasil. Os relatórios FAPESP anos I e II (INPD, 2018, 2019) nos fornecem alguns dados importantes, tais como o tamanho da amostra selecionada $(\mathrm{n}=2.511)$, as fases da investigação, além de dados sobre as diferentes categorias em análise nessa pesquisa e descritas a seguir.

De acordo com o modelo explicativo da psiquiatria do desenvolvimento, o fenoma comportamental refere-se a dados sobre cognição, emoçóes, temperamento, sintomas ou diagnósticos psiquiátricos dos participantes; o genoma diz respeito a dados colhidos em exames genéticos; o enviroma, por sua vez, refere-se às questóes ambientais tais como relacionamento familiar ou ainda acesso à serviços de saúde; dados sobre o fenoma cerebral dizem respeito às características observáveis do cérebro individual dos pesquisados e são obtidos por meio de exames de neuroimagem; e por último, o epigenoma e o proteoma, que são dados referentes a RNA, proteínas, enzimas presentes no sangue dos participantes. Conforme especialistas, todas essas dimensóes estão relacionadas, são interdependentes e investigadas com vistas a se poder fornecer futuramente um escore de risco para transtorno mental, consideradas caso a caso.

Os participantes realizaram, portanto, baterias de exames de sangue, genético e de neuroimagem ${ }^{7}$ - Ressonância Magnética Estrutural (RM) por Tensores de Difusão (DTI) e de Conectividade Funcional (FC) -, além de entrevistas com psicólogos da equipe para entender aquilo que se chama de "fatores ambientais" (que representam a dimensão social considerada), os quais, a propósito, são reduzidas ao contexto microssocial dos sujeitos, de suas interrelaçóes mais imediatas, ou seja, estes são definidos

7 Neste caso, apenas uma subamostra: 780 participantes. 
em relação a maus-tratos, dificuldades no desenvolvimento de habilidades parentais, violências domésticas, antecedentes de transtornos mentais na família, além de alguns dados socioeconômicos. Atualmente, o programa Conexão: mentes do futuro segue em andamento e se prevê sua finalização no ano de 2022 (INPD, 2018, 2019).

Criou-se também um site (INPD, [20--]) $)^{8}$ com o objetivo de se abrir um canal de comunicação com os participantes e onde é possível verificar o uso de uma linguagem que não apenas facilita o entendimento do público-alvo, como também o seduz a continuar na pesquisa:

Seu filho cresceu e nós evoluímos com ele. Tão importante quanto trabalhar em prol de ampliar o conhecimento em saúde mental na infância e adolescência no Brasil é dividir os resultados e trocar experiências com a sociedade. Mais que diagnosticar possíveis problemas que seu filho possa apresentar, o Projeto CONEXÃO Mentes do Futuro tem como objetivo primordial valorizar as potencialidades dele. Por isso, é fundamental que você assuma o compromisso de manter seu filho no Projeto. Mesmo que ele já tenha recebido algum retorno, continuaremos fazendo avaliações que serão realizadas e analisadas por alguns dos melhores profissionais do mundo, e de graça. Nesta fase, os profissionais do Projeto disponibilizam as seguintes informações: avaliação detalhada de dificuldades emocionais, como ansiedade e depressão; avaliação detalhada de dificuldades com comportamento, como déficit de atenção/hiperatividade; avaliação específica sobre dificuldades de aprendizagem; profissional pronto a esclarecer suas dúvidas e encaminhar para ajuda especializada; avaliação geral da saúde física. (INPD, [20--], grifos meus).

É importante notar, neste trecho, que dificuldades emocionais, de comportamento e aprendizagem são imediatamente traduzidas para o público leigo como diagnósticos psiquiátricos, já segundo a última revisão do manual de diagnósticos e estatísticas para transtornos mentais - o DSM-V (2014) - e são apresentados como verdades inquestionáveis de forma naturalizada.

Um dos principais objetivos do programa Conexâo: mentes do futuro é o de poder comparar, por meio de ampla base de dados de imagem cerebral obtidos em diferentes momentos da vida dos participantes, indivíduos que apresentaram um neurodesenvolvimento normal com aqueles que apresentaram desvios e, assim, poder correlacioná-los a outros fatores

8 Disponível em: http://www.conexaomentesdofuturo.com.br/home 
de risco de diferentes naturezas que possam estar presentes na vida desses sujeitos. A psiquiatria do desenvolvimento fundamenta-se, portanto, na ideia de que o cérebro começa a se desenvolver ainda na fase embrionária e é constante e progressivamente modelado no sentido de uma maturação que está sujeita à influência de diversos fatores (genéticos, bioquímicos, ambientais). O desenvolvimento cerebral típico/normal implica, portanto, processos de maturação que correspondem a aquisiçóes de certas habilidades cognitivas, emocionais e sociais.

Conforme Miguel (ZORZETTO, 2016), a hipótese principal com a qual se trabalha, em linhas gerais, é: situaçóes repetidas de maus-tratos físicos e psicológicos e outros eventos estressantes experenciados na infância e adolescência interagem continuamente com os genes que determinam a vulnerabilidade para problemas psiquiátricos. Essa interaçáo gene-ambiente gera alteraçóes no funcionamento e na estrutura das redes cerebrais. "A partir de determinado ponto, as alteraçóes acumuladas se tornariam suficientes para produzir os sintomas das doenças psiquiátricas" (ZORZETTO, 2016, p. 48). Em publicação da revista FAPESP: Uma longa maturaçâo: imagens de ressonância magnética funcional começam a revelar os padróes de desenvolvimento das redes cerebrais e desvios que podem indicar futuros transtornos psiquiátricos (2016), afirma-se:

Por trás da busca de marcadores de risco, há o reconhecimento cada vez maior da natureza médica dos transtornos mentais. "As doenças psiquiátricas não são mais entendidas só como transtornos da mente ou distúrbios de comportamento", explica Bressan, "são também doenças do cérebro, um órgão complexo e de grande plasticidade, que é altamente influenciada pelo ambiente, em especial pelas interações sociais". (ZORZETTO, 2016, p. 47, grifos meus).

Sustenta-se que existe uma maior potência desta ou daquela aquisição de habilidade ocorrer dentro de uma faixa etária esperada, em um marco cronológico do desenvolvimento; assim, a psiquiatria pretende propor intervenções a partir dessas "janelas terapêuticas” - entendidas também como as "janelas de vulnerabilidade" do neurodesenvolvimento infantil - com o objetivo de prevenir um desenvolvimento atípico (JACKOWSKI, 2019). De acordo com Rohde (ZORZETTO, 2016), importante pesquisador do INPD e também conselheiro de diversos laboratórios farmacêuticos (Eli-Lilly, Janssen-Cilag, Medice, Novartis, Shire), ao identificar mais cedo e até mesmo antes de se caracterizar como doença, objetiva-se aumentar a 
eficiência dos tratamentos, que é hoje limitada. Fica claro, portanto, que a proposta da identificação cada vez mais precoce dos transtornos mentais traz a possibilidade de se aplicar intervençóes também cada vez mais precoces, inclusive medicamentosas.

Nesse sentido, ao descobrir não apenas um único marcador de risco no indivíduo, mas uma combinação deles de diferentes naturezas suscetível de promover um neurodesenvolvimento atípico, sustenta-se que será possível, a partir da comprovaçáo desta hipótese, realizar intervençóes que interrompam o desenvolvimento do transtorno e que, portanto, curem o indivíduo de uma doença náo manifesta, a qual ele carrega de forma latente nos marcadores e que pode evoluir progressivamente, a menos que exista e que se aplique tal intervenção preventiva. Prevenção e cura aparecem, portanto, como sinônimos na medida em que o indivíduo teria a possibilidade de ser trazido, por meio de intervençóes preventivas personalizadas, de volta a uma trajetória normal de neurodesenvolvimento e, assim, nunca ver tornada manifesta sua doença. Percebe-se, portanto, a possibilidade de um redimensionamento do consumo de psicofármacos, da população já classificada com transtornos mentais, para todo indivíduo considerado de risco para desenvolvê-los.

Contudo, salienta-se que, para a frustração da comunidade psiquiátrica, os exames de ressonância magnética funcional podem ser usados atualmente apenas em pesquisas e não como ferramenta diagnóstica. Mas esse objetivo continua sendo intensamente perseguido nos estudos mais atuais. Segue, a título de exemplo, resumo do capítulo de livro (recém publicado): Network analysis of neuropsychiatry disorders (GUZMAN et al., 2020) ${ }^{9}$ que apresenta mais um novo subcampo em psiquiatria: a psiquiatria de precisão. Dentre os autores, aparece Sato, pesquisador da equipe INPD, especialista em matemática aplicada, e responsável pelo desenvolvimento e pela programaçáo de novas tecnologias:

A psiquiatria de precisão é um novo subcampo da medicina de precisão, impulsionado pelos recentes avanços na neurociência. O principal objetivo da psiquiatria de precisão é combinar os pacientes com os melhores tratamentos, com base não apenas nas características clínicas gerais, mas também em análises cuidadosas de suas características individuais em vários níveis (por exemplo, genética, estrutura e função cerebral). Aqui, fornecemos des-

9 https://www.sciencedirect.com/science/article/pii/B9780I28191781000393 
crições detalhadas dos métodos computacionais comumente usados para construir (isto é, correlação e causalidade de Granger) e analisar (isto é, métricas de integração e segregação, motivos, centralidade e entropia de rede) redes cerebrais funcionais. Em seguida, discutimos as implicações do desenvolvimento de novas abordagens e tecnologias matemáticas para promover diagnóstico e tratamento psiquiátricos precisos. Finalmente, também discutimos algumas linhas contínuas de investigação e oportunidades nesse novo e interessante campo de investigação interdisciplinar. (GUZMAN et al., 2020, p. 397, tradução minha).

De acordo com Jackowski (2019), existem hoje mais argumentos e evidências que corroboram a hipótese desenvolvimental dos transtornos psiquiátricos no caso da esquizofrenia (transtorno psicótico), devido a um maior número de estudos já realizados. A pesquisadora, vinculada ao INPD, traz como exemplo alguns dados obtidos a partir do Programa de Reconhecimento e Intervenção para Indivíduos em Estados Mentais de Risco (PRISMA) da UNIFESP, criado em 2010 e já finalizado. Esse estudo, que não consta dos relatórios FAPESP analisados, criou um serviço ambulatorial que teve como objetivo recrutar 100 crianças e acompanhá-las por dois anos no intuito de identificar quais estariam em risco de desenvolver um transtorno psicótico. É importante observar que, também neste caso, o recrutamento de participantes foi realizado junto às escolas.

Destaca-se aqui um apontamento feito por Bressan, coordenador do eixo pesquisa do INPD e diretor do Laboratório de Neurociências Clínicas da UNIFESP (LiNC), para a agência FAPESP:

Hoje, aproximadamente $20 \%$ dos indivíduos em risco acompanhados pelo Prisma convertem para a doença, ou seja, efetivamente desenvolvem um episódio psicótico. Talvez possamos reduzir esse índice se tratarmos com substâncias neuroprotetoras no momento certo. Neuroprotetores agiriam da mesma forma que as estatinas nas doenças cardiovasculares, que não têm impacto depois que a doença está instalada, mas podem funcionar na prevenção. [...] Para desenvolvermos novas drogas capazes de prevenir a esquizofrenia precisamos trabalhar nas fases iniciais do desenvolvimento da doença. (TOLEDO, 2015, [s. p.], grifos meus).

Mais uma vez, evidencia-se a intenção dos estudos conduzidos pelo INPD em colaborar para o desenvolvimento de novas drogas: os neuroprotetores, atendendo aos interesses mercadológicos da indústria farmacêutica. 


\section{As estratégias de disseminação dos saberes especializados em psiquiatria do desenvolvimento}

Dentre as estratégias de disseminação da psiquiatria do desenvolvimento na sociedade, merecem destaque: a formaçáo de novos especialistas e o processo de nucleação em outras universidades; a difusão dos conhecimentos produzidos entre os profissionais de saúde em geral, sobretudo aqueles atuantes na rede pública; e a disseminaçáo dos saberes especializados na sociedade em geral, principalmente no universo escolar.

Conforme relatórios FAPESP anos I e II (INPD, 2018, 2019), foi criado, em 2017, o Programa Especial de Cooperação Tripartite em Psiquiatria Translacional do Desenvolvimento (TPTD) - programa de pós-graduação em nível de doutorado que tem o objetivo de formar pesquisadores de ponta na área de psiquiatria, neurociências e saúde mental com ênfase nas fases iniciais do desenvolvimento. Reunindo as especialidades de cada um dos programas de pós-graduação em psiquiatria das três universidades vinculadas ao INPD (USP, UNIFESP e UFRGS), o TPTD concentra a formação em áreas estratégicas tais como a neurociência populacional, a neurociência clínica e a prevenção de transtornos mentais à luz dos achados de neurociência. Até abril de 2019, quando da escrita do segundo relatório à FAPESP, três alunos haviam concluído o programa, e outros seis ainda estavam cursando.

Com o TPTD, pretende-se também estimular novos profissionais e grupos de pesquisa de departamentos psiquiátricos emergentes selecionados no país para incorporar o referencial da psiquiatria do desenvolvimento, processo chamado de nucleação. Três estados brasileiros foram selecionados para avançar nesse sentido: Bahia, Goiás e Ceará. São alunos do Programa Internacional Tripartite que têm o compromisso de retornar aos seus estados e iniciar processo de desenvolvimento local de programas de pós-graduação e de reproduzir, assim, formação de recursos humanos para a docência e pesquisa com foco em psiquiatria do desenvolvimento. Isto é, com essa iniciativa, espera-se difundir nacionalmente o novo referencial no campo acadêmico, concorrendo para torná-lo hegemônico.

Outra iniciativa importante é a criação do Curso de Especialização em Saúde Mental da infância e Adolescência (CESMIA) que tem como 
foco a disseminaçáo dos saberes em psiquiatria do desenvolvimento entre os profissionais de saúde em geral. Criado pela Unidade de Psiquiatria da Infância e Adolescência (UPIA) da UNIFESP, este curso é dirigido a um público multiprofissional e traz como objetivo a capacitação em saúde mental de profissionais com nível superior da área de saúde - não apenas médicos - que atendam crianças e adolescentes em instituições preferencialmente públicas, no âmbito do Sistema Único de Saúde (SUS). Em funcionamento desde 2012, até a escrita do último relatório FAPESP, 120 participantes do CESMIA haviam se formado (INPD, 2019).

Sob a justificativa de que os transtornos psiquiátricos na infância têm sido subdiagnosticados e subtratados, pretende-se generalizar o enquadramento da infância admitida como problemática nas classificações diagnósticas em psiquiatria. Destaca-se, nesse sentido, que tais iniciativas concorrem para uma medicalização generalizada no país dos comportamentos infantis socialmente indesejados (FOUCAULT, 2010), tais como a indisciplina, a irritabilidade, a desatenção, a hiperatividade, os quais são comumente vistos, por exemplo, como entraves a um bom desempenho escolar. A partir do encaminhamento de crianças por educadores ou pais às unidades de saúde por problemas emocionais/comportamentais, espera-se que todos os profissionais abordem tais questôes já sob o viés da psiquiatria do desenvolvimento.

No que se refere à difusão dos saberes especializados em psiquiatria do desenvolvimento na sociedade em geral, é importante perceber que, na esteira das revoluçóes tecnológicas e do imperativo da vida digital do século XXI, o INPD vai se inserir completamente nessa nova realidade, mobilizando uma variedade de técnicas e recursos tecnológicos tanto no âmbito da comunicação, como na prática diagnóstica e terapêutica. Ressalta-se que diversos congressos no mundo ${ }^{10}$, incluindo o último congresso realizado no Brasil (ROHDE et al., 2019)"', colocam o debate

10 A exemplo do 15th World Congress of Biological Psychiatry a acontecer em Viena em junho de 2021 . O tema central é "Precision Psychiatry in the Era of Artificial Intelligence and New Technologies". The Congress will feature plenaries, symposia, workshops and posters that will highlight the advances in the fields of drug discovery, genomics, imaging, omics, cognitive neuroscience, digital and clinical phenotyping, e-mental health and virtual care, and how artificial intelligence can leverage such advances to aid personalized treatment of people with mental disorders and addictions. Disponível em: https://www.wfsbp-congress.org/.

II Disponível em: http://www.cbpabp.org.br/cbp20।9/ 
sobre a psiquiatria no mundo digital e propóem soluçóes em psiquiatria a partir do uso de inteligência artificial. Portanto, este é um debate muito atual e de extrema relevância e nos leva a questionar sobre os impactos dessas novas configuraçóes em psiquiatria ao processo de medicalização da vida na contemporaneidade.

No que diz respeito à comunicação, além do site (página eletrônica) institucional do INPD - criado para que a população interessada possa ter acesso a conhecimentos em linguagem acessível e também pleitear participação nas pesquisas em andamento -, há outros sites que veiculam informaçóes sobre a psiquiatria do desenvolvimento e os diversos programas vinculados ao INPD. Segundo relatório FAPESP ano II (INPD, 2019), foram criados o site "www.saudementalnaescola.com" e uma cartilha psicoeducativa ${ }^{12}$ on-line para professores com o intuito de orientá-los na identificação das diferentes situaçóes que envolvem as questóes de saúde mental na infância e na adolescência no cotidiano escolar. Essa cartilha visa a instrumentalizar manejos e, quando necessário, dar sequência aos encaminhamentos para atendimentos especializados e redes de apoio para os casos em que se observam situaçóes atípicas no desenvolvimento.

O programa Cuca Legal ${ }^{13}$, por sua vez, atua em diversos cenários e desenvolve açóes customizadas de acordo com o conteúdo, público (educadores, pais e alunos), número de encontros e recursos disponíveis, isto é, desenvolve e vende serviços em diferentes modalidades: cursos, palestras, consultorias, bate-papo com especialistas e pesquisas em diferentes temas, tais como: saúde mental, competências socioemocionais, álcool e outras drogas. Também no âmbito do Cuca Legal, merece destaque o lançamento do livro Saúde Mental na Escola: o que os educadores devem saber (ESTANISLAU; BRESSAN, 2015) o qual, conforme o site, tem sido citado como "livro de cabeceira" por educadores em todo o Brasil. Foi escrito em coautoria com pesquisadores especialistas nos diversos temas abordados no livro. É pertinente observar que, embora os autores se afirmem contrários ao processo de medicalização (entendido aqui como supervalorização da doença), das suas 263 páginas, mais

I2 Texto em PDF acessível em: https://docs.wixstatic.com/ugd/IbdIb6_da952d88498343cd88bbf50el30aba27. pdf

13 Disponível em: http://cucalegal.org.br/ 
de 160 foram dedicadas a descrever os transtornos mentais mais comuns na infância - que, como vimos, são diagnósticos criados e multiplicados a partir de pressupostos epistemológicos bastante frágeis -, além de orientar sobre como abordá-los e manejá-los.

Com esta investigaçáo, foi possível observar um discurso que enfatiza a promoção de saúde mental nas escolas, evitando a supervalorização da doença, e que está disponível para o público leigo e também educadores em sites, cartilhas e no livro acima referido. Contudo, artigos científicos publicados a partir dessas mesmas experiências de inserção da psiquiatria do desenvolvimento no ambiente escolar produzem um discurso diferente com foco na intervenção e diagnóstico, tal como no trecho abaixo, abstract do artigo Evaluating the effectiveness of a training program that builds teachers' capability to identify and appropriately refer middle and high school students with mental health problems in Brazil: an exploratory study (VIEIRA et al., 2014).

No Brasil, como em muitos países, tem havido uma falha na identificação de problemas de saúde mental (PSM) em crianças e jovens e em encaminhá-los para os cuidados e apoio adequados. O ambiente escolar fornece um cenário ideal para isso. Portanto, programas eficazes precisam ser desenvolvidos para treinar professores para identificar e encaminhar adequadamente crianças com possível PSM. Nosso objetivo foi avaliar a capacidade dos professores em identificar e encaminhar adequadamente os alunos com um possível PSM e a eficácia de uma estratégia psicoeducacional para aumentar a capacidade dos professores nessa área. (VIEIRA et al. 2014, p. I, tradução minha).

Ainda no âmbito do Cuca Legal, está em desenvolvimento um sistema de inteligência artificial (CleverCare ${ }^{14}$ ) na área de saúde mental. Por meio de estudo piloto em duas escolas públicas do município de Jabuticabal/ SP, esta iniciativa visa ao desenvolvimento e à avaliação de um sistema eletrônico interativo de suporte via celular para educadores em parceria com a empresa Kidopi-Soluçóes em Informática Médica. Segundo relatório FAPESP ano II (INPD, 2019) tal sistema possibilita a troca de mensagens e informaçóes sobre situaçóes relacionadas à saúde mental vivenciadas pelos educadores no ambiente escolar. O CleverCare pode ser entendido, portanto, como um sistema de gestão de riscos que possui interfaces gráficas

14 Disponível em: www.clevercare.com.br 
para usuários, um sistema de gestão de diálogos além da integração com serviços de mensagens como WhatsApp e SMS (INPD, 2019).

Ressalta-se, uma vez mais, que essas diversas iniciativas da psiquiatria do desenvolvimento no Brasil envolvendo o mundo digital e o universo escolar expressam a existência em curso de uma nova tentativa de legitimação e fortalecimento do poder psiquiátrico no governo dos sentimentos e condutas de crianças e adolescentes, e este se impóe especialmente na escola. A este respeito, Giusti (2016, p. 169) defende que:

A educação escolar que se apresenta na atualidade segue fortemente influenciada pelos ideais higienistas. A profilaxia e sanitarismo a que se referiam tais ideais justificaram e legitimaram a atuação de profissionais do campo médico, como pediatras, psicólogos e psiquiatras no campo da educação, justamente por este ser considerado o ambiente de formação do caráter e criação de hábitos. A infância ainda é vista como período primordial de prevenção das doenças mentais e, cabe aos professores e agentes da educação identificá-las e corrigi-las a tempo.

Nota-se, portanto, que existem muito mais continuidades do que rupturas no discurso psiquiátrico ao longo da história. Criam-se novas tecnologias prático-discursivas, mas os pressupostos se baseiam sempre nas mesmas ideias e seus objetivos continuam majoritariamente relacionados ao mesmo problema epistemológico: a origem orgânica das patologias mentais. Cabe assinalar, contudo, que a partir das mais recentes transformaçôes tecnológicas e dos meios de comunicação, as quais ganham força com a entrada no século XXI, vê-se ampliar fortemente as possibilidades de intervenção da psiquiatria no governo das condutas humanas, ou seja, na gestão social.

\section{Considerações finais}

O propósito deste trabalho não foi o de tentar deslegitimar levianamente os conhecimentos e as práticas do campo biomédico, tampouco aquelas em análise aqui privilegiadas: a psiquiatria de viés biológico/organicista e suas vertentes mais recentes. Como vimos, críticas relacionadas a inconsistências teóricas e metodológicas emergem do próprio campo da psiquiatria, e revelam a existência de um embate discursivo pela afirmaçáo e legitimação de certas verdades no interior dele. 
Assim, o grande desafio que se apresenta às ciências sociais no que se refere às questóes de saúde mental é, fundamentalmente, o de chamar a atenção para as fragilidades epistemológicas da psiquiatria desde sua constituição e as estratégias que são mobilizadas para, a despeito delas, não perder legitimidade no universo acadêmico-científico e fora dele. Outra questão correlata refere-se ao determinismo biológico de suas explicações, isto é, à sua obsessão por descobrir um marcador biológico para as patologias mentais, e concomitantemente, à sua negligência histórica em considerar os aspectos sociais, políticos e culturais mais amplos do sofrimento psíquico $^{15}$, ou seja, suas multideterminaçóes. Considerada, portanto, a dificuldade histórica na comprovação da existência de marcadores biológicos confiáveis para transtornos mentais, a psiquiatria trata agora de atualizar a legitimidade de seus saberes em conexão com o modelo neurocientífico adotando seus pressupostos.

Destaca-se, por fim, que a psiquiatria do desenvolvimento, que é essencialmente "biologicista" e preventiva, ao ancorar-se na noção de risco e ao tornar cada vez mais difusas as características entre aquilo que é normal e patológico no campo das condutas e dos sentimentos humanos, está contribuindo fortemente para o processo de medicalização da vida na contemporaneidade, sobretudo no domínio da infância e adolescência. Algumas das consequências ético-políticas, que se evidenciam com a mobilização dessas novas estratégias biopolíticas e analisadas aqui, incluem: a multiplicação de diagnósticos psiquiátricos na infância; o aumento da estigmatização de crianças e o impacto na construção de suas subjetividades; a biologização e individualização do sofrimento psíquico alicerçada na negligência de seus condicionantes sociais; além do crescimento da medicamentalização, ou seja, da prescrição de psicofármacos com graves efeitos colaterais, alguns com alto poder adictivo (a exemplo das anfetaminas), no manejo com crianças e adolescentes.

Nesse sentido, defende-se que entender o sofrimento psíquico para além do cérebro ou dos genes, ou, ainda, para além das categorias psiquiátricas, significa reconhecer sua complexidade e multideterminação, signifi-

15 Essas questões foram amplamente discutidas na dissertação a partir da qual se origina este artigo. Interessados na temática podem solicitar acesso ao trabalho integral. 
ca situar novamente os sujeitos náo apenas em seus contextos micro, mas também macrossociais, significa, então, devolver-lhes suas histórias de vida e permitir que eles tenham uma relação mais autônoma e menos estigmatizante com a própria subjetividade. Afinal, não se trata de desconsiderar a nossa dimensão orgânica, mas tão somente de apontar a dificuldade histórica que ainda resiste na compreensão epistemológica sobre a articulação entre o biológico e o social, ambas condiçóes da existência humana.

\section{Referências}

ASSOCIAÇÃO AMERICANA DE PSIQUIATRIA. DSM-V: Manual Diagnóstico e Estatístico de Transtornos Mentais. 5. ed. Porto Alegre: Artmed, 2014.

BASE NACIONAL COMUM CURRICULAR (BNCC). Competências socioemocionais como fator de proteçáo à saúde mental e ao bullying. 2018. Disponível em:

http://basenacionalcomum.mec.gov.br/implementacao/praticas/caderno-de-praticas/ aprofundamentos/195-competencias-socioemocionais-como-fator-de-protecao-a-saude-mental-eao-bullying. Acesso em: 9 out. 2019.

BRUNONI, A. R. Beyond the DSM: trends in psychiatry diagnoses. Arch. Clin. Psychiatry (São Paulo), São Paulo, v. 44, n. 6, p. 154-158, Dez. 2017. Disponível em: http://www.scielo.br/scielo. php?pid=S0101-60832017000600154\&script=sci_arttext. Acesso em: 7 ago. 2019.

CAMPOS, M. Projeto brasileiro de Psiquiatria investiga desenvolvimento típico e atípico em crianças e adolescentes. 09 out. 2019. Disponível em: https:/www.unifesp.br/reitoria/dci/ releases/item/4085-projeto-brasileiro-de-psiquiatria-investiga-desenvolvimento-tipico-e-atipicoem-criancas-e-adolescentes. Acesso em: 9 out. 2019.

CAPONI, S. N. C. de. Da herança biológica à localização cerebral: sobre o determinismo biológico de condutas indesejadas. Physis [online], v. 17, n. 2, p. 343-352, 2007. Disponível em: http:// www.scielo.br/scielo.php?pid=S0103-73312007000200008\&script=sci_arttext\&tlng=pt. Acesso em: 3 maio 2018.

CAPONI, S. Classificar e medicar: a gestão biopolítica dos sofrimentos psíquicos. R. Inter. Interdisc. INTERthesis, Florianópolis, jul./dez. 2012, p.101-122. Disponível em: https://periodicos.ufsc.br/ index.php/interthesis/article/view/1807-1384.2012v9n2p101. Acesso em: 5 set 2018.

CAPONI, S. N. C. de. Uma sala tranquila: neurolépticos para uma biopolítica da indiferença. 1. ed. São Paulo: LiberArs, 2019.

CASTEL, R. La Sociedad Contemporánea ¿es una sociedad de riesgo? Conferencia. Buenos Aires: Secretaría de Gabinete y Gestión Pública, 2 set 2008. Disponível em: http://www. derechoshumanos.unlp.edu.ar/assets/files/documentos/la-sociedad-contemporanea-es-unasociedad-de-riesgo.pdf. Acesso em: 5 maio 2019. 
CASTIEL, L. D.; ALVAREZ-DARDET, C. La salud persecutória: los limites de la responsabilidad. 1. ed. Buenos Aires: Lugar Editorial, 2010.

DUTRA, C. M. Bases etiológicas da esquizofrenia: rumo a uma nova frenologia? Orientador: Antonio Lucio Teixeira Junior. 2004. 37 f. Monografia (Especialização em Neurociências e Comportamento) - Instituto de Ciências Biológicas, Universidade Federal de Minas Gerais, Belo Horizonte, 2004.

ESTANISLAU, G. M.; BRESSAN, R. A. (org.). Saúde mental na escola: o que os educadores devem saber. Porto Alegre: Artmed, 2014.

FOUCAULT, M. O poder psiquiátrico: curso no Collège de France (1973-1974). São Paulo: Martins Fontes, 2006.

FOUCAULT, M. Em defesa da Sociedade: Curso no Collége de France (1975-1976). 3. ed. São Paulo: Martins Fontes, 1999

FOUCAULT, M. Segurança, território, população. São Paulo: Martins Fontes, 2008.

FOUCAULT, M. Os anormais. São Paulo: Editora WMF Martins Fontes, 2010.

FOUCAULT, M. Microfísica do poder. São Paulo: Edições Graal, 2011.

FRANCES, A. Fundamentos do diagnóstico psiquiátrico: respondendo as mudanças dos DSM5. Porto Alegre: Artmed, 2015.

GIUSTI, K. G. A medicalizaçáo da infância: uma análise sobre a psiquiatrização da infância e sua influência na instituição escolar. 2016. 220 f. Dissertação (Mestrado em Sociologia Política) - Programa de Pós-Graduação em Sociologia Política, Centro de Filosofia e Ciências Humanas, Universidade Federal de Santa Catarina, Florianópolis, 2016.

GUZMAN, G. E. C.; BALARDIN, J. B.; BIAZOLI, C. E.; SATO, J.; FUJITA, A. Network analysis of neuropsychiatry disorders. Elsevier-Academic Press, p. 397-408, 2020. Disponível em: https:// www.sciencedirect.com/science/article/pii/B9780128191781000393. Acesso em: 10 jan. 2020.

INSTITUTO NACIONAL DE CIÊNCIA E TECNOLOGIA DE PSIQUIATRIA DO DESENVOLVIMENTO PARA A INFÂNCIA E ADOLESCÊNCIA (INPD). Relatório FAPESP ano I. jun. 2018. Disponível em: http://inpd.org.br/wp-content/uploads/2018/08/ Relatorio-_INPD-Fapesp2018-10.pdf. Acesso em: 2 maio 2019.

INSTITUTO NACIONAL DE CIENNCIA E TECNOLOGIA DE PSIQUIATRIA DO DESENVOLVIMENTO PARA A INFÂNCIA E ADOLESCÊNCIA (INPD). Relatório FAPESP ano II. jun. 2019. Disponível em: http://inpd.org.br/wp-content/uploads/2019/07/ Relatorio_INPD_FAPESP2019.pdf. Acesso em: 5 jul. 2019.

INSTITUTO NACIONAL DE CIENCIA E TECNOLOGIA DE PSIQUIATRIA DO DESENVOLVIMENTO PARA A INFÂNCIA E ADOLESCENCIA (INPD). Projeto Conexáo: Mentes do Futuro. [20--]._Disponível em: http://www.conexaomentesdofuturo.com. br/. Acesso em: 6 jul. 2019. 
INSTITUTO NACIONAL DE CIENNCIA E TECNOLOGIA DE PSIQUIATRIA DO DESENVOLVIMENTO PARA A INFÂNCIA E ADOLESCÊNCIA (INPD). 2020. Disponível em:_http://www.inpd.org.br. Acesso em: 6 jul. 2019.

JACKOWSKI, A. Neurodesenvolvimento e Transtornos Mentais. [s. l.]: Instituto Brasileiro de Psicofarmacologia e Farmacogenética, 16 jan. 2019. 1 vídeo $(59$ min 28 seg). Disponível em: https://www.youtube.com/watch?v=nX3miGDIZt8\&t=127s. Acesso em: 1 nov. 2019.

MIGUEL, E. C.; MERCADANTE, M. T; GRISI, S.; ROHDE, L. A. O Instituto Nacional de Ciência e Tecnologia de Psiquiatria do Desenvolvimento para a Infância e Adolescência: um novo paradigma para a Psiquiatria Brasileira tendo como foco as nossas crianças e o seu futuro. Rev. Bras. Psiquiatr., São Paulo, v. 31, n. 2, 2009._Disponível em: http://www.scielo.br/scielo.php?script=sci_ arttext\&pid=S1516-44462009000200001. Acesso em: 10 mar. 2018.

MITJAVILA, M. Medicalização, risco e controle social. Tempo Soc., São Paulo, v. 27, n. 1, 2015. Disponível em: http://www.scielo.br/scielo.php?pid=S0103-20702015000100117\&script=sci_ abstract\&tlng=pt. Acesso em: 6 jul. 2019.

MORAES, C. et al. Força-tarefa brasileira de psiquiatras da infância e adolescência. Rev. Bras. Psiquiatr, São Paulo, v. 30, n. 3, 2008. Disponível em: http://www.scielo.br/scielo.php?script=sci_ arttext\&pid=S1516-44462008000300021. Acesso em: 9 jan. 2018.

ORTEGA, F. O corpo transparente: visualização médica e cultura popular no século XX. Hist, Ciênc, Saúde Manguinhos, v. 13, n. suplemento, 2006. Disponível em: http://www.scielo.br/scielo. php?pid=S0104-59702006000500006\&script=sci_abstract\&tlng=pt. Acesso em: 7 ago. 2019.

ORTEGA, F.; VIDAL, F. Somos nosso cérebro? Neurociências, subjetividade, cultura. N-1 ediçôes. São Paulo, 2019.

ORTEGA, F.; ZORZANELLI, R. Cultura somática, neurociências e subjetividade contemporânea. Psic. e socied. [online], v. 23, n. especial, 2011. Disponível em: http://www.scielo.br/scielo. php?pid=S0102-71822011000400005\&script=sci_abstract\&tlng=pt. Acesso em: 6 set. 2019.

POLANCZYCK, G. Em busca das origens desenvolvimentais dos transtornos mentais. Rev. Psiq. RS. v. 31, n. 1, 2009. Disponível em: http://www.scielo.br/scielo.php?pid=S0101$81082009000100005 \&$ script=sci_abstract\&tlng=pt. Acesso em: 11 jan. 2019.

RABINOW, P. Antropologia da Razão. Relume Dumará: Rio de Janeiro, 1999.

ROHDE, L. A. Uso da neurociência é o próximo desafio dos psiquiatras, diz médico brasileiro. Folha de S. Paulo, 07 jan. 2013. Entrevista concedida a Rafael Garcia. Disponível em: https:// www1.folha.uol.com.br/equilibrioesaude/2013/01/1210439-uso-da-neurociencia-e-o-proximodesafio-dos-psiquiatras-diz-medico-brasileiro.shtml. Acesso em: 6 maio 2019.

ROHDE, L. A. et al. Quem deve tratar crianças e adolescentes? O espaço da psiquiatria da infância e da adolescência em questão. Rev. Brasil. Psiqu., São Paulo, v. 22, n. 1, 2000. Disponível em: http://www.scielo.br/scielo.php?script=sci_arttext\&pid=S1516-44462000000100002. Acesso em: 13 jan. 2019. 
ROHDE, L. A. et al. Entrevista. Debates: psiquiatria hoje, v. 1, n. 1. São Paulo: Associação Brasileira de Psiquiatria, 2009. Disponível em: http://www.cbpabp.org.br/hotsite/wp-content/ uploads/2020/01/rbp_40.pdf. Acesso em: 3 fev. 2019.

ROSE, N.; ABI-RACHED, J. M. The birth of the neuromolecular gaze. Hist. Human Scienc. [UK], v. 23, n. 1, p. 11-36, 2010. Disponível em: https://journals.sagepub.com/doi/ abs/10.1177/0952695109352407. Acesso em: 8 jun. 2019.

ROSE, N.; ABI-RACHED, J. M. Neuro: The New Brain Sciences and the Management of the Mind. Princeton: Princeton University Press, 2013.

TOLEDO, K. Consórcio busca avançar na prevenção da esquizofrenia. In: Agência Fapesp. 22 de maio de 2015. Disponível em: http://agencia.fapesp.br/consorcio_busca_avancar_na_ prevencao_da_esquizofrenia/21201/. Acesso em: 6 out. 2018.

UTTAL, W. The New Phrenology: The Limits of Localizing Cognitive Processes in the Brain. Cambridge, MA: MIT Press, 2001.

VIEIRA, M. A; GADELHA, A. A; MORIYAMA, T. S; BRESSAN, R. A; BORDIN, I. A. Evaluating the effectiveness of a training program that builds teachers' capability to identify and appropriately refer middle and high school students with mental health problems in Brazil: an exploratory study. BMC Public Health, n. 14, v. 1, 2014. Disponível em: https://bmcpublichealth. biomedcentral.com/articles/10.1186/1471-2458-14-210. Acesso em: 28 out. 2019.

ZORZETTO, R. Uma longa maturação. In: Revista Pesquisa FAPESP. Edição 232, p.46-53, Jun. 2015. Disponível em: https://revistapesquisa.fapesp.br/2015/06/16/uma-longa-maturacao/. Acesso em: 10 jul. 2019. 


\section{New approaches in childhood and adolescence psychiatry in XXI century Brazil: focus on prevention and risk control}

\section{Abstract}

In this article, the emergence and dissemination of specialized knowledge in developmental psychiatry for childhood and adolescence in Brazil were discussed. A bibliographic and documentary investigation was carried out - in which I highlight an analysis of the reports (INPD, 2018, 2019) describing its researches and activities - and through which it was possible to observe that these new arrangements in psychiatry arise from of its approach to neurosciences in the last decades, and configure a theoretical model whose foundations are based on explanations about brain development. By establishing a research agenda with children and teenagers, recruited directly from some selected schools, specialists in developmental psychiatry aim to identify, at an earlier age, individuals at risk of developing mental disorders and, thus, create diagnostic and therapeutic technologies that work in the scope of prevention. The analysis of the initiatives carried out by this group of psychiatrists - researchers at the University of São Paulo (UNIFESP), Federal University of São Paulo (USP) and Federal University of Rio Grande do Sul (UFRGS) - over the past decade allows us to state that the legitimation and diffusion of this new psychiatry's paradigm in society contributes strongly to the expansion of the medicalization of childhood and of the school space within the country.

Keywords: Developmental psychiatry. Prevention. Risk control. Medicalization of childhood. 